\title{
Training in psychotherapy: a call for embodied and psychophysiological approaches
}

\author{
Alessandro Gennaro, ${ }^{1}$ Johann Roland Kleinbub, ${ }^{2}$ Stefania Mannarini, ${ }^{2}$ Sergio Salvatore, ${ }^{1}$ Arianna Palmieri ${ }^{2,3}$ \\ ${ }^{1}$ Department of Dynamic and Clinical Psychology, "La Sapienza" University of Rome; ${ }^{2}$ Department of Philosophy, Sociology, Education \\ and Applied Psychology, University of Padua; ${ }^{3}$ Padua Neuroscience Center, University of Padua, Italy
}

\begin{abstract}
Psychotherapy research studies are increasingly focused on the clinical process, which has allowed for the definition of general models about clinical functioning and the role of the therapist. Embodiment-based research has shown that interpersonal processes, such as synchrony and attunement, are critical for the development of crucial therapist skills and that these mechanisms are mediated by physiological processes. Although the connection between these embodied processes and clinical practice is currently a topic of investigation in psychotherapy research, its implications for clinical training are potentially broad, but they remain unexplored. The present contribution proposes the idea of embodied trainings for psychotherapy trainees, which could support their acquisition of clinical skills through implicit, embodied, and affective learning. We present detailed potential mechanisms, study designs, and psychological variables that could be used to develop such an in vivo training and suggest some possible applications, ranging from biofeedback sessions to experimental settings and roleplaying. Additional research in this field can help bridge the gap between psychotherapy research and psychotherapy training, by overcoming some of the limitations of post-session and external evaluations, by enriching psychotherapy training programs, and by facilitating the implicit and automatic attunement of the attitudes of the students who will become tomorrow's therapists.
\end{abstract}

Key words: Clinical training; Embodiment; Process research; Psychotherapy.

\section{Introduction}

Psychotherapy process research seeks to identify factors that can explain how clinical encounters work and

Correspondence: Arianna Palmieri, Department of Philosophy, Sociology, Education and Applied Psychology, University of Padua, via Venezia 14, 35211 Padua, Italy.

E-mail: arianna.palmieri@unipd.it

Citation: Gennaro, A., Kleinbub, J. R., Mannarini, S., Salvatore, S., \& Palmieri, A. (2019). Training in psychotherapy: a call for embodied and psychophysiological approaches. Research in Psychotherapy: Psychopathology, Process and Outcome, 22(3), 333-343. doi: 10.4081/ripppo.2019.395

Contributions: all the authors contributed to the drafting of the manuscript according to their specific expertise in the subject.

Conflict of interest: The authors declare no potential conflict of interest.

Funding: None.

Received for publication: 29 March 2019

Revision received: 4 September 2019.

Accepted for publication: 26 September 2019.

This work is licensed under a Creative Commons Attribution NonCommercial 4.0 License (CC BY-NC 4.0).

${ }^{\circ}$ Copyright: the Author(s), 2019

Licensee PAGEPress, Italy

Research in Psychotherapy:

Psychopathology, Process and Outcome 2019; 22:333-343

doi:10.4081/ripppo.2019.395 their role in promoting specific outcomes. As suggested by Orlinsky, Rønnestad and Willutzki (2004), it focuses on specific happenings and events observed in therapy, including (primarily) the actions, experiences and relatedness of patient and therapist in therapy sessions when they are physically together (p. 311). A huge number of empirical studies have resulted in a variety of approaches (single case studies, intensive clinical analysis, naturalistic studies, etc.) and strategy analyses (application of standardized tools, hermeneutic approaches, narrative analysis, etc.). However, to date, there exists no comprehensive theory of clinical functioning (Salvatore \& Gennaro, 2015), nor any recognized unified framework that would allow researchers to assess therapeutic processes independently of therapeutic orientation (Tryon, 2016).

This gap in the research is reflected into three different factors. First, the field of clinical psychology is highly fragmented, and there are many theoretical approaches (e.g., psychodynamic, cognitive, humanistic) that barely interact with each other (Salvatore, 2011). Second, the spread of idiosyncratic identifying factors as explanations for clinical functioning has prevented an integrative perspective about psychotherapy phenomena, thereby undermining opportunities to create a shared perspective. Moreover, similar theoretical concepts, procedures, and phenomena are sometimes described using different terms, while at other times, the same terms are used to describe different or only partially overlapping phenomena (Block, 1996). Third, the reductionist research approach (Elliott \& Anderson, 1994; Stiles \& Shapiro, 1994), which 
is now widely used in psychotherapy research (Gennaro, Gelo, Lagetto, \& Salvatore, 2019), seeks to isolate and identify specific variables that reflect constructs that are assumed to be vectors of change. This approach hinders researchers' ability to identify a general model that can explain the clinical working process (Crits-Christoph, Chambless, \& Markell, 2014; Laska, Gurman, \& Wampold, 2014; Tschacher \& Pfammatter, 2016).

The identification of interdisciplinary constructs and wider explicative models common to different psychotherapeutic approaches could help overcome such theoretical - and hence clinical - fragmentation (Marks, 2005; Salvatore \& Gennaro, 2015). A step in this direction was offered by the field's corporal turn (Vermes, 2011), which offers a new approach to the field of clinical psychology. The spread of the embodied perspective, which takes the body into consideration in psychological research (Shaw, 2004), has crucially helped to integrate research on psychological and physiological processes by acknowledging the physical body as the basis of human subjectivity and intersubjectivity (Crossley, 1995; Varela, Thompson, \& Rosch, 1992).

The increasing popularity of this approach has pushed scientific research to consider physiological processes as markers that may offer insightful information about the psychological functioning at both the intra- and interpersonal levels. The deepening of the latter has been further encouraged by the spread of embodiment-based research in psychotherapy process research, which has focused on the interaction of the clinical dyad (Kleinbub, 2017; Kleinbub et al., 2019; Marci, Ham, Moran, \& Orr, 2007; Messina et al., 2013; Palmieri, et al., 2018a; Palmieri, Palvarini, Mangini, \& Schimmenti, 2018; Rocco et al., 2017). Concepts such as synchrony, attunement, and mutual regulation are now acknowledged by clinicians and researchers as both the bases of interpersonal processes and as general models that can help to explain the clinical processes (Vacharkulksemsuk \& Fredrickson, 2012). In other words, the identification of constructs shared by different approaches, beyond the research on common factors - i.e., active ingredients of psychotherapy shared by different approaches (McAleavey \& Castonguay, 2015) represent a possibility for detecting a unifying framework among researchers and clinicians. Accordingly, we are persuaded that a relational and embodied perspective could be useful in this direction, and we claim for the adoption of an embodied perspective since the beginning of the training for future therapists throughout the introduction of protocols that have never been applied to date, to the best of our knowledge. However, from a theoretical point of view, the frameworks have already been provided by seminal authors. For instance, Beebe and Lachmann (2002) suggested that the internalization of relational patterns in infancy - expressed by co-regulated, synchronized phenomena between mother and child at both the behavioral and psychophysiological levels - can shape in- fants' internal working models, which are in turn transferred and re-actuated in adulthood, especially in therapeutic relationships. Consistently, Ham and Tronic (2009) highlighted, through their still-face paradigm (Tronick, Als, Adamson, Wise, \& Brazelton, 1978), that reunion episodes, in which a mother and infant both attempt to recoordinate their behavioral and physiological systems to generate a new attunement and repair a previous relational rupture, are characterized by higher psychophysiological synchronization; presumably, the same phenomenon occurs during rupture-reparation processes in psychotherapy (Beebe et al., 2010), a clinical dynamic which is increasingly studied as interpersonal (Miller-Bottome et al., 2018, 2019).

The role of physiological processes is indeed a current topic of investigation in patient-therapist relationship research (for a review, see Kleinbub, 2017) in the perspective of self-regulation and co-regulation. For instance, a study by Marci and Orr (2006) found that increased emotional distance is associated with decreased psychophysiological concordance and reduced subjective ratings of perceived empathy (p. 115), supporting the use of physiological synchrony as a potential marker to manage empathy in clinical interviews. Even the Dynamic Complex Systems meta-model - in its whole - suggests that it might be possible to detect a general model of clinical functioning comprising psychological and physiological processes. In this model, clinical changes could be described as ruptures followed by resynchronization between the two elements of an interacting dyad (Gelo \& Salvatore, 2016) and such co-regulating processes occur via synergistic mechanisms (e.g., Kelso, 2009) involving physiological variables.

Despite the understanding of physiological processes in psychotherapeutic approaches is considered a key for the management of clinical encounters (Lackner \& Fresco, 2016; Mehling et al., 2009), mainstream research has not yet addressed the broad implications of this approach for clinical training (Tschacher, Munt, \& Storch, 2014; Tschacher, Storch, \& Munt, 2014). Notwithstanding that empirical research has highlighted the role of physiological factors in achieving clinical psychotherapy outcomes, the activation and management of such factors remains unexplored, as well as there has been no research on how to train psychotherapy students about these factors. Some previous research has emphasized the role of regulative processes in psychophysiological activation, both within a framework of a dynamic diagnostic process that can deepen a therapist's understanding through sensory perception and collaborative exploration (Ham \& Tronick 2009; Ramseyer, Tschacher, 2011), and in therapeutic practice as way to shape and nourish the relational dialogue that links verbal and non-verbal communication (Rocco, Gennaro, Salvatore, Stoycheva, \& Bucci, 2017). However, this works has been perceived as descriptors of the way that clinical relationships work. In other terms, 
psychophysiological factors are typically accounted as post-hoc explicative models, which provide little information to clinicians about how to acknowledge psychophysiological variables and, most importantly, about how to manage them in ongoing clinical processes.

Such an impasse is reflected in current psychotherapy training programs, which seek to develop students' clinical skills as future psychotherapy practitioners using evidence-based studies, seminars and courses, clinical practice, supervision, and personal therapy. This learning approach enriches students' knowledge about successful psychotherapy settings and allows them to deploy and test clinical techniques in clinical relationships; however, it gives students no opportunities to gain awareness of their own physiological activation and its role in developing psychological processes as pathways that convey specific techniques during clinical sessions.

Accordingly, the main aim of this paper is focused on a proposal to encourage pivotal therapist training programs, as a context to develop the embodied therapist skills. This could improve students' clinical skills and abilities to manage clinical situations by moving from an informed training approach - that is, training based on post-session and external evaluations of effective interventions identified by the literature - to an embodied training approach - that is, a training based on trainees' abilities to acknowledge and improve own psychophysiological awareness and understand its usefulness as a method for gathering information about the applied clinical processes, thereby improving the students' abilities to manage clinical situations. As matter of facts therapists' awareness concerning the role of embodied variables, could lead to improved management of the therapeutic relationship and patient participation, toward what De Jaegher and Di Paolo (2007) called participatory sense-making.

The first part of the present paper focuses on clinical and research interest in the interpersonal roles of embodied processes, highlighting the role of psychophysiology in interpersonal relationships and demonstrating the utility of more direct research efforts to develop biofeedbacklike approaches in psychotherapy training programs. Such an approach could increase psychotherapy students' body awareness and abilities to identify and manage their own clinically relevant psychophysiological processes in support of their clinical goals. The second part of this paper suggests possible applications of embodied learning approaches for psychotherapy trainees, by an in vivo training program. The paper concludes with remarks on the utility of embodied learning training programs as a way to bridge the gap between clinical training and practice.

\section{Mind-body: from clinical evidence to current research results}

The body-mind issue was central to the birth of psychoanalysis and the development of its epistemological structure. As highlighted in the previous section, it continues to be a core issue for modern clinicians and researchers. Beginning with Breuer and Freud's (1893-1895) initial hysteria studies, the body held a central role, and Freud himself considered the psychic apparatus to be a specialization of the body's somatic functions; he believed that over a certain threshold, an energy phenomenon of somatic origin could become psychic (Palmieri et al., 2018b). Even the concept of drive, which Freud $(1915,1920)$ set among the pillars of his Metapsychology, is rooted in the liminal territory between the psychic and the somatic. Freud's focus on bodily markers as pathways with which to reconstruct a connection with the unconscious during the transference/countertransference process thus seems to have been the main clinical intervention at the dawn of psychoanalysis.

Twentieth century clinical research strongholds also did not lack for authors who favored clinical approaches that could bridge somatic and psychological observations. For example, Winnicott (1949/1992) conceived the psyche as the source of the imaginative elaboration of the somatic components of feelings and functions, and therefore of physical life: The mind did not really exist as an entity; rather the psyche referred to the imaginative elaborations of somatic parts, feelings and functions, that is, of physical aliveness (p. 244). Similarly, Bion (1963) argued that alternations between concretization and abstraction represented a continuum ranging from bodily sensations to representative phenomena.

More recently, the intersubjective perspective (Storolow, 2013; Storolow, Atwood, \& Branchaft, 1994) has theorized that human phenomena are products not of isolated intrapsychic mechanisms, but of mutual interactions between embodied subjects.

The understanding of other persons is fully embodied in the sense of being based on the resonance between clinicians' body and the other's body, with the other given in his expressive bodily presence (Atwood \& Storolow, 2014). Intersubjectivity is thus a sensorimotor, proprioceptive apprehension of others that is situated in the context of preverbal communication based on affective attunement and an implicit procedural, non-symbolic, and pre-reflective code (Atwood \& Storolow, 2014; Gallese, 2013; Gallese \& Cuccio, 2015; Storolow, 2011). Moreover, although a strong mind-body connection has long been considered to be relevant in clinical psychology, only in recent decades the field's corporal turn highlighted how cognitive processes consist in mapping ongoing bodily modifications (Damasio, 1996, 1999, 2006). Psychological phenomena are thus grounded in the body, especially in an organism's sensory-motor experiences (Glenberg, 2010; Price, Peterson, \& Harmon-Jones, 2012; Winkielman, Niedenthal, Wielgosz, Eelen, \& Kavanagh, 2015) and social interactions (Fuchs, 2009). Overall, embodied cognition hypothesizes a functional unity between sensory-motor, corporeal experiences and cognitive/per- 
ceptual processes. Information processing is influenced and/or modified by body experiences (Jirak, Menz, Buccino, Borghi, \& Binkofski, 2010; Winkielman et al., 2015): cognitions and emotions develop in the sensorimotor experience of the environment (Fuchs \& Schlimme, 2009; Price et al., 2012), and such shaping drives interactions with the environment itself (Barsalou, 2005; Fuchs, 2009; Glenberg, 2010; Glenberg, Wit, \& Metcalfe, 2013; Meteyard, Cuadrado, Bahrami, \& Vigliocco, 2012).

Although a patient's and therapist's coordination of their body signals does not fully cover all the possibilities of studying embodiment in a clinical setting, it has probably been the most fecund source of findings in the field. A huge number of published studies have shown that a patient and her or his therapist tend to have reciprocal non-verbal synchronization during psychotherapy (Tschacher \& Pfammatter, 2016); for instance, they have been shown to display coupled patterns in vocal pitch (Imel et al., 2014), head movements (Ramseyer \& Tschacher, 2014), and whole body movements (Ramseyer \& Tschacher, 2011, 2014). Moreover, interesting clinical outcome prediction results have emerged from the study of non-verbal synchronization in psychotherapy. For example, Ramseyer and Tschacher (2014) investigated patients' and therapists' coordination of various body regions and found that head synchrony predicted the therapy's global outcome while body synchrony predicted the session's outcome. In the same vein, Rocco et al. (2017) found that psychotherapy characterized by attunement mechanisms tended to have good outcomes, likely due these processes' reinforcement of the patienttherapist relationship.

In a recent review, Palumbo et al. (2017) investigated psychophysiological synchronization in different human relationships, including mother-child, romantic couple, patient-therapist, and teammate relationships. Their study highlighted how interpersonal physiological phenomena have been associated with various psychological constructs, such as empathy (e.g., Marci et al., 2007), stress contagion (e.g., Waters, Wes, \& Mendes, 2014), attachment security (e.g., Diamond, Hicks, \& Otter-Henderson, 2008), conflict (e.g., Levenson \& Gottman, 1983), and emotional regulation (e.g., Field, 2012), and have been proposed as indices of relational efficacy in various contexts, such as teamwork (e.g., Chanel, Kivikangas, \& Ravaja, 2012), couples (e.g., Helm, Sbarra, \& Ferrer, 2014), and psychotherapy/counseling (e.g., Marci \& Riess, 2005). Palumbo et al. (2017) concluded that psychophysiological synchronization likely helps to be informative of the state of a relationship (p. 29). Kleinbub (2017) analyzed 19 studies that focused on the synchronization of interpersonal physiology indices in clinical contexts and concluded that the majority of studies reported a positive association between psychophysiological synchronization and empathy, although most studies did not explicitly refer to a specific model or definition of empathy. Marci and Orr (2006) and Marci et al. (2007) likewise found a direct correlation between the amount of patient-therapist psychophysiological synchronization and the level of empathetic understanding that patients felt from their therapists. In addition, Palmieri et al. (2018) demonstrated that priming the sense of attachment security in therapists influenced their psychophysiological synchronization in clinical dyads, as compared with a control group in which therapists received a prime not related to attachment, a result in line with novel developments in the attachment field suggesting that therapists of different attachment classifications may attune to patients in distinct ways (Talia et al., 2018).

These findings suggest the idea that the shared psychophysiological activation can represent an eligible candidate of a somatic mirror mechanism, as suggested by Oberman and Ramachandran (2008), by means of a joint functioning of the cardiac and electrodermal dynamics, underlying the idea of engagement dynamics (Di Paolo \& De Jaegher, 2012). Moreover, from a complementary neuroscience perspective, as suggested by Kleinbub et al. (2019), there is indeed a strong link between autonomic physiology and central nervous system mirror mechanisms due to the central autonomic network (CAN), which is thought to serve as a crucial link between the brain and physiological dynamics (Beissner, Meissner, Bär, \& Napadow, 2013; Gallese, 2013). The CAN includes the anterior cingulate, the ventromedial prefrontal, the insular cortex, the amygdala, and the hypothalamus and is more active in the right hemisphere. These interconnected components, together with higher-order cortical functions that regulate the response of subcortical structures, seem to control the autonomic input and output of psychophysiological variables, such as heartbeats and electrodermal activity. This functional and anatomic link between central and peripheral areas suggests that the physiological regulations that are negotiated during the interpersonal exchange in clinical interaction, are directly connected to crucial functions of our brains related to empathy. In other words, it may be possible to indirectly study the functioning of Mirror Neuron System by using psychophysiological techniques (Ramachandra, Depalma, \& Lisiewski, 2009, p. 683).

Overall, almost all of the research cited here can be taken to suggest that psychophysiological synchronization is easily achieved via simple means, occurs under a variety of conditions, and is in fact hard to avoid (De Jaegher \& Di Paolo, 2008; Palumbo et al., 2017).

\section{The importance of embodiment in clinical training programs}

The increased research interest in the role of physiological reactions in clinical processes has demonstrated that therapists perceive and make use of all sorts of physiological information within therapy sessions, but that this information is not always a conscious influence (Palmieri 
et al., 2018b). On the other hand, embodied perspective acknowledges bodily experience as way through which therapists make sense of their therapeutic encounters since the knowledge of the therapeutic encounter can be acquired somatically by psychotherapists (Shaw, 2004). Nevertheless, recognizing their own bodily contribution is not an easy task for therapists, nor is any relevant training provided to psychotherapy students. We therefore argue for the need to dedicate research efforts to developing interpersonal physiology measures that can be used as clinical tools to detect the continuous implicit adjustments that occur between a patient and therapist and which could define a new set of objective, in vivo, and (in most cases) automatic measurements. Psychotherapy training programs would be enriched by the adoption of such modern technologies in empirically supported training protocols, and this would furthermore help address the oft-lamented research-practice gap by offering psychotherapy students different opportunities to explore their own embodied reactions, as well as management strategies that could be used in professional practice. Just to present some suggestions to clarify this point, a curriculum for embodied psychotherapy training could include, for example, topics such as the body as a receiver, embodied styles of working, and body empathy.

However, this perspective would require a rethinking of psychotherapy's formative training setting. As previously noted, embodiment should not be approached by informed learning mechanisms (i.e., lectures and the analysis of published research and case studies); instead, the development of bodily awareness requires direct experiences in which students can refine their abilities to perceive, identify, feel, and manage their own psychophysiological reactions. Clinical interventions indeed are basically actions pragmatic - obviously clinically driven - dealing with the management of a social relationship. Thus the enriching of skills aimed at managing such situation arise in light of the experience of one's own even bodily - activation in the clinical relationship itself.

Our proposal does not preclude the continued inclusion of informed learning methods; rather, it suggests the need to include an additional and specific settings in which students' learned knowledge could be directly experienced and observed in order to increase their awareness, and, as a result, their ability to manage learned skills in professional practice. As matter of facts, the main goal of clinical training is to increase students' awareness of the use and management of different techniques in clinical settings. Effective use of clinical techniques entails clinicians' ability to make use of their own bodily activation as a tool, to direct the choice of technique appropriate to a specific clinical situation, rather than to simply transmit knowledge about the techniques.

In a broader view, the inclusion of embodied training perspectives in clinical training programs entail a rethinking of the skills that characterize professional clinical practice. Skills cannot be reduced to the use specific techniques, rather, clinical ability crucially rely on the therapist's biological and physiological self-monitoring abilities which need to be trained. Now a day, psychotherapy training programs do not include any opportunities for students to apply embodied training techniques.

The rest of this section therefore suggests three potential embodiment training methods that could be empirically developed. The following three proposals, related to the possible developments of the introduction of the embodiment in clinical training programs, are rooted in the theoretical frameworks mentioned above, in particular the systemicdyadic model of Beebe and Lachmann (2002), and are inspired by the assumptions of the results obtained by the empirical studies on shared physiology in psychotherapy, presented in the first section of the manuscript.

\section{Proposal 1. Biofeedback sessions for trainees}

Broadly speaking, biofeedback consists of a procedure in which participants receive real-time information about their own physiological activity in an intuitive way, such as through auditory or visual stimuli. This information can then be used to train participants to regulate their basic autonomic and visceral functions, such as skin conductance, skin temperature, cardiac activity, and muscular tension. A typical application is training patients to relax, which is achieved by collecting one or more indices of arousal and stress (e.g., skin conductance) and providing a visual representation, for instance through a colored bar on a computer monitor that increases and decreases according to the patient's arousal level; an operator then typically instructs the patient to try to decrease the bar's level. Successful regulation may be further boosted through positive and negative reinforcements. Generally speaking, biofeedback training has been observed to facilitate the mitigation of various physical and psychological conditions, including anxiety, depression, chronic pain, headache, and fibromyalgia (Andrasik \& Rine, 2007).

Analogously to the above-mentioned biofeedback training protocols classically applied to patients, psychotherapy trainees can gradually learn the mechanisms through which bodily states can be voluntarily influenced by various mental processes. The development of this control can allow them to become more aware of the mental processes reflected by the feedback, thus facilitating the associated mechanisms, such as emotional regulation, which may in turn play key roles in the clinical process. For example, Chandler et al. (2001) found that biofeedback-assisted relaxation training could effectively reduce stress-related symptoms and enhance personal well-being in a group of counseling students enrolled in a basic counseling skills course. Similarly, implementing biofeedback sessions for psychotherapy students could improve the students' awareness of their own physiological responses to different stressors. In addition, such biofeedback sessions could provide a setting in which future practitioners could test different 
ways of managing their physiological responses without the ethical implications of involving a patient.

\section{Proposal 2. Specific experimental settings}

Another method to improve psychotherapy students' physiological awareness could be the implementation of a specific experimental setting that combines clinical vignettes with psychophysiological data. The use of vignettes as an experimental condition is widespread across a range of scientific fields and professional disciplines; for example, recent work by Evans et al. (2015) demonstrated that vignettes provide specific non-naturalistic settings that allow for the investigation of a number of phenomena in the social, behavioral, and health sciences (e.g., Alexander \& Becker, 1978; Bachmann et al., 2008; Mannarini \& Boffo, 2015; Mannarini, Boffo, Rossi, \& Balottin, 2018; Wallander, 2009), as well as in other professional disciplines, such as business, marketing, and economics (e.g., Wason, Polonsky, \& Hyman, 2002); social and experimental psychology (e.g., Jones \& Aronson, 1973); sociology (Wallander, 2009); developmental psychology (e.g., Howie, Nash, Kurukulasuriya, \& Bowman, 2012); and education and school psychology (Baudson \& Preckel, 2013). Extending the use of clinical vignettes into clinical training, in association with physiological response measurements (e.g., heart rate, skin conductance, body motion data), could provide future practitioners with a way to increase their awareness of their own physiological responses to the specific conditions defined by the vignette, thus allowing them to observe how their choice of a specific technique could be considered the result of their own need to reduce their physiological activation rather than a choice driven entirely by a clinically informed decisionmaking process. The ultimate goal of these specific experimental settings is thus not to evaluate the choices made by students, but rather to allow them to increase their selfawareness of their physiological reactions, their correlations with specific clinical choices, and methods to manage their physiological responses in clinical situations.

Vignettes, and experimental conditions in general, allow for the manipulation of specific aspects of a stimulus while controlling others. Vignette-based experimental designs and other experimental settings could be applied to physiological monitoring by offering students opportunities to observe how an individual's thoughts, feelings, behaviors, and decisions are affected by factors that may not be easily accessible due to their embodied nature. This issue is of great interest to health care research in general, and more specifically to psychotherapy treatment, since a practitioner's judgments and actions can have enormous implications for patients. Thus, despite the low external validity of vignettes and experimental settings (they typically represent ad hoc settings that would rarely be found in real life), they could nonetheless be an ideal method of investigating how clinicians' bodily reactions affect their decisions, which in turn affect their patients.

\section{Proposal 3. Roleplays and session simulations}

Clinical session simulation, and role play could be considered as dramas in which participants are temporally involved in adopting a role and try to behave according to such role. Role play are powerful but often neglected teaching techniques (Steinert, 1993) that can promote skill acquisition by enabling students to define a problem, develop solutions, and receive feedback on new behaviors. Structured roleplays direct students to think about what occurs in a roleplay, as well as the value of the roleplay, both before and after participating in the session. This prompts students to draw on their prior experiences - an important component of adult learning that also promotes reflection. Roleplays have been traditionally used in medical education as a method to teach communication strategies (Charlton, 1993; Hargie, Dickson, Boohan, \& Hughes, 1998), as well as in a range of other disciplines with learners of various ages, as a method to help students acquire knowledge, attitudes, and skills (e.g., language skills [Steinert, 1993], cross-cultural training [Skelton, Hammond, Fitzmaurice, \& Wiskin, 1997], and business and human resources skills [Nestel, Muir, Plant, Kidd, \& Thurlow, 2002]). Recent work by Komer (2005) demonstrated that the use of roleplay techniques in teaching can serve as an effective substitute for and supplement to simulation technology, since they provide students with riskfree opportunities to practice clinical skills and develop clinical judgment.

While the use of roleplaying is common in psychotherapy training programs, enhancing these simulations with real-time information about each individual's physiological activity could increase the value of the roleplay trainings by enhancing the role-play trainings by casting light over embodied processes of the clinical relationship which are often below the consciousness threshold. More specifically, developing and employing interpersonal biofeedback procedures (Hawlitschek, Teubner, Lux, \& Adam, 2015; Kassel \& LeMay, 2015) during clinical roleplays could not only inform students about the state of their own physiological activity but could also allow them to receive moment-by-moment feedback about their physiological synchronization with the roleplaying patient. While this approach presents potential confounders that need to be considered when planning the practical implementations (e.g. the emotional influence of the biofeedback device itself), the previously cited literature suggests that this type of feedback could effectively help students to both enhance their empathic skills and to recognize ruptures (and pathways for their resolution) in their clinical relationships.

\section{Limitations}

These three proposals, chosen for their relative simplicity, represent just a few of the possible methods that could help psychotherapy trainees in developing abilities 
in acknowledging the embodied nature of clinical relationship and make use of bodily reactions to manage clinical situations that could be extended in professional practice life. These three proposals, which could easily be applied in clinical training programs, deal respectively with acknowledging the therapist's own bodily reactions (the first two proposals) and unveiling the embodied nature of the clinical bond (the third proposal), as well as with acknowledging the reciprocal physiological effects of clinical interventions and clinical relationships. It is important to note that all the proposals and ideas presented in this article imply a certain degree of practical complexity. For instance, researchers motivated to implement these proposals will be faced with fundamental questions such as which kind of physiological signal(s) to choose, how to set up the acquisition devices, how to process and analyze the data, etc. An answer to these issues would go broadly beyond the scope of this article, and we refer the interested reader to the recent publication by Kleinbub, Talia, and Palmieri (2019). Similarly, it must be acknowledged that the implementation of this embodied approaches presents a non-negligible cost, in terms of time, equipment, and personnel expertise. Nonetheless we strongly believe that it is a well worth investment, and that through the accumulation of evidence from pilot studies and technological advancements, this cost will quickly decrease, leading to a mainstream adoption of these instruments and ideas.

\section{Conclusions}

An established unified framework that allows for the assessment of therapeutic processes independently of therapeutic orientation (Tryon, 2016) is still missing from the field. This state of art brings to bear three critical issues that hamper the possibility of delineating a broad, integrated psychotherapy model: the redundancy of the many theoretical approaches that scarcely interact with each other, the idiosyncratic polysemy of the factors used to explain clinical functioning, and the reliance on reductionist therapeutic approaches. Although embodiment still has a long way to go as a unifying concept in the field of psychology (Glenberg, 2010), emergent clinical paradigms and research advances have increasingly demonstrated its relevance in clinical relationships. The increasing evidence about its effects on perceptions of ongoing relationships suggests that we are on the right track in bringing psychology research back to its roots: the identification of a general metatheoretical model that can explain clinical processes. Importantly, shared physiologically-informed training may also lead psychotherapy students to act contextually in order to interact with patients at an embodied level. For instance, embodiment's recursive effects, which can also be seen as transitions in physiological synchrony and as signs of rupture-recovery episodes, rather than as an average of absolute values of synchronization, may provide good indications of moments in which habitual patterns of behavior change.

In order to assign value to and make sense of these observations, which are spread across the theoretical and empirical subfields of psychology but have not yet been applied in clinical practice, the present contribution focused on embodiment's potential application in psychotherapy students' training. From our standpoint, embodied training opportunities are highly necessary for future practitioners: current clinical training largely consists of informed training, such as lectures, even though it is increasingly clear that mental processes are insufficiently understood using frameworks of symbolic manipulation and information processing alone (Tschacher \& Dauwalder, 2003). Psychotherapy training should therefore not only investigate and theorize about embodiment but should also apply research evidence in clinical trainings. This requires that embodied phenomena be viewed through a wider lens and incorporate practices from livedbody paradigms. This is likely to be an uncomfortable process, since it will require an analysis of the discourse currently used within the profession, and, by implication, will necessitate a critique of current psychotherapy training curricula.

Physiologically-informed training may lead trainees to act in order to encounter patients at embodied level. For instance, acknowledge these recursive effects, which can appear also as transitions in bodily synchrony as sign of breakdown-recovery episodes, or the looking at transitions in bodily synchrony markers as indications of moments in which habitual patterns of behavior change.

For many years, researchers and practitioners have sought to bring research closer to real-life practice. Perhaps in the present case we should instead refer to the need to bring a real-life issue - clinical training practices - closer to research. We do not pretend that our present contribution is exhaustive, but we hope that it can shed some light on an impasse situation: the need to train competent therapists at a relational level requires that they learn to recognize and manage even embodied components. Training students to be more aware of clinical psychotherapy's embodied dimensions during their formative training could thus be a way to increase the skills of tomorrow's therapists.

\section{References}

Alexander, C. S., \& Becker, H. J. (1978). The use of vignettes in survey research. Public Opinion Quarterly, 42(1), 93-104. doi: $10.1086 / 268432$

Andrasik, F., \& Rime, C. (2007). Biofeedback. In S. D. Waldman (Ed.), Pain management (pp. 1010-1020). Philadelphia, PA: Saunders/Elsevier.

Atwood, G. E., \& Stolorow, R. D. (2014). Structures of subjectivity: Explorations in psychoanalytic phenomenology and contextualism. London, UK: Routledge/Taylor \& Francis Group. 
Bachmann, L. M., Mühleisen, A., Bock, A., ter Riet, G., Held, U., \& Kessels, A. G. (2008). Vignette studies of medical choice and judgement to study caregivers' medical decision behaviour: systematic review. BMC Medical Research Methodology, 8(1), 50. doi: 10.1186/1471-2288-8-50

Barsalou, L. W. (2005). Situated conceptualization. In H. Cohen, \& C. Lefebvre (Eds.), Handbook of categorization in cognitive science (pp. 619-650). Amsterdam: Elsevier Science.

Baudson, T. G., \& Preckel, F. (2013). Teachers' implicit personality theories about the gifted: An experimental approach. School Psychology Quarterly, 28(1), 37. doi: 10.1037/ spq0000011

Beebe, B., Jaffe, J., Markese, S., Buck, K., Chen, H., Cohen, P.,... \& Feldstein, S. (2010). The origins of 12-month attachment: A microanalysis of 4-month mother-infant interaction. Attachment \& Human Development, 12(1-2), 3-141. doi: 10.1080/14616730903338985

Beebe, B., \& Lachmann, F. M. (2002). Infant research and adult treatment: Co-constructing interactions. New York, NY, US: The Analytic Press/Taylor \& Francis Group.

Beissner, F., Meissner, K., Bär, K. J., \& Napadow, V. (2013). The autonomic brain: an activation likelihood estimation meta-analysis for central processing of autonomic function. Journal of Neuroscience, 33(25), 10503-10511. doi: 10.1523/JNEUROSCI.1103-13.2013

Bion, W. R. (1963). Elements of psychoanalysis. London, UK: Routledge/Taylor \& Francis Group.

Block, J. (1996). Some jangly remarks on Baumeister and Heatherton. Psychological Inquiry, 7, 28-32. doi: 10.1207/ s15327965pli0701_5

Breuer, J., \& Freud, S. (1893-1895). Studies on hysteria. In J. Strachey (Ed.). (1955). The standard edition of the complete psychological works of Sigmund Freud, Volume II (18931895). London, UK: Hogarth Press.

Castonguay, L. G. (2009). Marvin Goldfried's (1980) American Psychologist paper: (Re) Introducing a classic. Applied and Preventive Psychology, 13(1-4), 1. doi: 10.1016/j.appsy. 2009.10.010

Chandler, C., Bodenhamer-Davis, E., Holden, J. M., Evenson, T., \& Bratton, S. (2001). Enhancing personal wellness in counselor trainees using biofeedback: An exploratory study. Applied Psychophysiology and Biofeedback, 26(1), 1-7. doi: 10.1023/A:1009548719340

Chanel, G., Kivikangas, J. M., \& Ravaja, N. (2012). Physiological compliance for social gaming analysis: Cooperative versus competitive play. Interacting with Computers, 24(4), 306-316. doi: 10.1016/j.intcom.2012.04.012

Charlton, R. C. (1993). Using role-plays to teach palliative medicine. Medical Teacher, 15(2-3), 187-193.

Comer, S. K. (2005). Patient care simulations: Role playing to enhance clinical understanding. Nursing Education Perspectives, 26(6), 357-361.

Crits-Christoph, P., Chambless, D. L., \& Markell, H. M. (2014). Moving evidence-based practice forward successfully: Commentary on Laska, Gurman, and Wampold. Psychotherapy, 51(4), 491-495. doi: 10.1037/a0036508

Cromby, J. (2012). Feeling the way: Qualitative clinical research and the affective turn. Qualitative Research in Psychology, 9(1), 88-98. doi: 10.1080/14780887.2012.630831

Crossley, N. (1995). Merleau-Ponty, the elusive body and carnal sociology. Body \& Society, 1(1), 43-63. doi: 10.1177/ 1357034X95001001004

Damasio, A. R. (1996). The somatic marker hypothesis and the possible functions of the prefrontal cortex. Philosophical Transactions of the Royal Society of London. Series B: Biological Sciences, 351(1346), 1413-1420. doi: 10.1098/rstb. 1996.0125

Damasio, A. R. (1999). The feeling of what happens: Body and emotion in the making of consciousness. New York, NY, US: Houghton Mifflin Harcourt.

Damasio, A. R. (2006). Descartes'error. London, UK: Random House.

De Jaegher, H., \& Di Paolo, E. (2007). Participatory sense-making. Phenomenology and the Cognitive Sciences, 6(4), 485507. doi: 10.1007/s11097-007-9076-9

De Jaegher, H., \& Di Paolo, E. (2008). Making sense in participation: An enactive approach to social cognition. In F. Morganti, A. Carassa, \& G. Riva (Eds.), Enacting intersubjectivity: a cognitive and social perspective on the study of interactions. emerging communication: studies in new technologies and practices in communication (pp. 3347). Amsterdam: IOS Press.

De Jaegher, H., \& Di Paolo, E. A. (2013). Enactivism is not interactionism. Frontiers in Human Neuroscience, 6, 345. doi: 10.3389/fnhum.2012.00345

Di Paolo, E. A., \& De Jaegher, H. (2012). The interactive brain hypothesis. Frontiers in Human Neuroscience, 6, 163. doi: 10.3389/fnhum.2012.00163

Diamond, L. M., Hicks, A. M., \& Otter-Henderson, K. D. (2008). Every time you go away: Changes in affect, behavior, and physiology associated with travel-related separations from romantic partners. Journal of Personality and Social Psychology, 95(2), 385. doi: 10.1037/0022-3514. 95.2.385

Elliott, R., \& Anderson, C. (1994). Simplicity and complexity in psychotherapy research. In R. L. Russell (Ed.), Reassessing psychotherapy research (pp. 65-113). New York, NY, US: Guilford Press.

Evans, S. C., Roberts, M. C., Keeley, J. W., Blossom, J. B., Amaro, C. M., Garcia, A. M.,... \& Reed, G. M. (2015). Vignette methodologies for studying clinicians' decision-making: validity, utility, and application in ICD-11 field studies. International Journal of Clinical And Health Psychology, 15(2), 160-170. doi: 10.1016/j.ijchp.2014.12.001

Field, T. (2012). Relationships as regulators. Psychology, 3(6), 467-479. doi: 10.4236/psych.2012.36066

Freud, S. (1915). Instincts and their vicissitudes. In J. Strachey (Ed.). (1957). The Standard Edition of the Complete Psychological Works of Sigmund Freud, Volume XIV (19141916) (pp. 109-140). London, UK: Hogarth Press.

Freud, S. (1920). Beyond the pleasure principle. In J. Strachey (Ed.). (1955). The Standard Edition of the Complete Psychological Works of Sigmund Freud, Volume XVIII (19201922). London, UK: Hogarth Press.

Fuchs, T. (2009). Embodied cognitive neuroscience and its consequences for psychiatry. Poiesis \& Praxis, 6(3-4), 219-233. doi: 10.1007/s10202-008-0068-9

Fuchs, T., \& Schlimme, J. E. (2009). Embodiment and psychopathology: a phenomenological perspective. Current Opinion in Psychiatry, 22(6), 570-575. doi: 10.1097/YCO.0b013e3283318e5c

Gallese, V., \& Cuccio, V. (2015). The paradigmatic body - embodied simulation, intersubjectivity, the bodily self, and language. In T. Metzinger, \& J. M. Windt (Eds.), Open MIND: 14(T). Frankfurt am Main: MIND Group.

Gallese, V. (2013). Mirror neurons, embodied simulation and a 
second-person approach to mindreading. Cortex, 49(10), 2954-2956. doi: 10.1016/j.cortex.2013.09.008

Gelo, O. C. G., \& Salvatore, S. (2016). A dynamic systems approach to psychotherapy: A meta-theoretical framework for explaining psychotherapy change processes. Journal of Counseling Psychology, 63(4), 379-395. doi: 10.1037/ cou0000150

Gennaro, A., Gelo, O., Lagetto, G., \& Salvatore, S. (2019). A systematic review of psychotherapy research topics (20002016): A computer-assisted approach. [Manuscript submitted for publication].

Glenberg, A. M. (2010). Embodiment as a unifying perspective for psychology. Wiley Interdisciplinary Reviews: Cognitive Science, 1(4), 586-596. doi: 10.1002/wcs.55

Glenberg, A. M., Witt, J. K., \& Metcalfe, J. (2013). From the revolution to embodiment: 25 years of cognitive psychology. Perspectives on Psychological Science, 8(5), 573-585. doi: $10.1177 / 1745691613498098$

Ham, J., \& Tronick, E. (2009). Relational psychophysiology: Lessons from mother-infant physiology research on dyadically expanded states of consciousness. Psychotherapy Research, 19(6), 619-632. doi: 10.1080/10503300802609672

Hargie, O., Dickson, D., Boohan, M., \& Hughes, K. (1998). A survey of communication skills training in UK schools of medicine: present practices and prospective proposals. Medical Education, 32(1), 25-34. doi: 10.1046/j.13652923.1998.00154.x

Hawlitschek, F., Teubner, T., Lux, E., \& Adam, M. T. (2015). Foreign live biofeedback: Using others' neurophysiological data. In F. Davis (Ed.), Information Systems and Neuroscience (pp. 59-64). Berlin: Springer.

Helm, J. L., Sbarra, D. A., \& Ferrer, E. (2014). Coregulation of respiratory sinus arrhythmia in adult romantic partners. Emotion, 14(3), 522-531. doi: 10.1037/a0035960

Howie, P., Nash, L., Kurukulasuriya, N., \& Bowman, A. (2012). Children's event reports: Factors affecting responses to repeated questions in vignette scenarios and event recall interviews. British Journal of Developmental Psychology, 30(4), 550-568. doi: 10.1111/j.2044-835X.2011.02064.x

Imel, Z. E., Barco, J. S., Brown, H. J., Baucom, B. R., Baer, J. S., Kircher, J. C., \& Atkins, D. C. (2014). The association of therapist empathy and synchrony in vocally encoded arousal. Journal of Counseling Psychology, 61(1), 146-153. doi: 10.1037/a0034943

Jirak, D., Menz, M. M., Buccino, G., Borghi, A. M., \& Binkofski, F. (2010). Grasping language-a short story on embodiment. Consciousness and Cognition, 19(3), 711-720. doi: 10.1016/j.concog.2010.06.020

Jones, C., \& Aronson, E. (1973). Attribution of fault to a rape victim as a function of respectability of the victim. Journal of Personality and Social Psychology, 26(3), 415. doi: 10.1037/h0034463

Kassel, S. C., \& LeMay, J. (2015). Interpersonal biofeedback: Biofeedback in a relationship context. Biofeedback, 43(4), 153-157. doi: 10.5298/1081-5937-43.4.07

Kelso, J. A. S. (1995). Dynamic patterns: the self-organization of brain and behaviour. Cambridge, MA: MIT Press.

Kelso, J. S. (2009). Coordination dynamics. In R. Meyers (Ed.), Encyclopedia of complexity and systems science (pp. 1-41). Springer: New York, NY.

Kleinbub, J. R. (2017). State of the art of interpersonal physiology in psychotherapy: a systematic review. Frontiers in Psychology, 8, 2053. doi: 10.3389/fpsyg.2017.02053
Kleinbub, J. R., Palmieri, A., Orsucci, F. F., Andreassi, S., Musmeci, N., Benelli, E.,... \& de Felice, G. (2019). Measuring empathy: A statistical physics grounded approach. Physica A: Statistical Mechanics and its Applications, 526, 120979. doi: 10.1016/j.physa.2019.04.215

Kleinbub, J. R., Talia, A., \& Palmieri, A. (2019). Physiological synchronization in the clinical process: a research primer. Journal of Counseling Psychology. doi: 10.1037/ cou0000383

Lackner, R. J., \& Fresco, D. M. (2016). Interaction effect of brooding rumination and interoceptive awareness on depression and anxiety symptoms. Behaviour Research And Therapy, 85, 43-52. doi: 10.1016/j.brat.2016.08.007

Laska, K. M., Gurman, A. S., \& Wampold, B. E. (2014). Expanding the lens of evidence-based practice in psychotherapy: A common factors perspective. Psychotherapy, 51(4), 467-481. doi: 10.1037/a0034332

Levenson, R. W., \& Gottman, J. M. (1983). Marital interaction: physiological linkage and affective exchange. Journal of Personality and Social Psychology, 45(3), 587. doi: 10.1037/0022-3514.45.3.587

Mannarini, S., \& Boffo, M. (2015). Anxiety, bulimia, drug and alcohol addiction, depression, and schizophrenia: what do you think about their aetiology, dangerousness, social distance, and treatment? A Latent Class Analysis approach. Social Psychiatry and Psychiatric Epidemiology, 50(1), 27-37. doi: 10.1007/s00127-014-0925-x

Mannarini, S., Boffo, M., Rossi, A., \& Balottin, L. (2018). Etiological beliefs, treatments, stigmatizing attitudes toward schizophrenia. What do Italians and Israelis think? Frontiers in Psychology, 8(1), 2289. doi: 10.3389/fpsyg.2017.02289

Marci, C. D., Ham, J., Moran, E., \& Orr, S. P. (2007). Physiologic correlates of perceived therapist empathy and socialemotional process during psychotherapy. Journal of Nervous and Mental Disease, 195(2), 103-111. doi: 10.1097/01. nmd.0000253731.71025.fc

Marci, C. D., \& Orr, S. P. (2006). The effect of emotional distance on psychophysiologic concordance and perceived empathy between patient and interviewer. Applied Psychophysiology and Biofeedback, 31(2), 115-128. doi: 10.1007/s10484-006-9008-4

Marci, C., \& Riess, H. (2005). The clinical relevance of psychophysiology: support for the psychobiology of empathy and psychodynamic process. American Journal of Psychotherapy, 59(3), 213-226. doi: 10.1176/appi.psychotherapy.2005.59.3.213

Marks, I. (2005). Common language for psychotherapy procedure. Behaviour Therapist, 28, 81-83.

McAleavey, A. A., \& Castonguay, L. G. (2015). The process of change in psychotherapy: Common and unique factors. In O. Gelo, A. Pritz, \& B. Rieken (Eds.), Psychotherapy research: Foundations, process and outcome (pp. 293-310). Vienna, Austria: Springer.

Mehling, W. E., Gopisetty, V., Daubenmier, J. J., Price, C. J., Hecht, F. M., \& Stewart, A. (2009). Body awareness: construct and self-report measures. PLoS One, 4(5), e5614. doi: 10.1371/journal.pone.0005614

Messina, I., Palmieri, A., Sambin, M., Kleinbub, J. R., Voci, A., \& Calvo, V. (2013). Somatic underpinnings of perceived empathy: The importance of psychotherapy training. Psychotherapy Research, 23(2), 169-177. doi: org/10.1080/10503307.2012.748940

Meteyard, L., Cuadrado, S. R., Bahrami, B., \& Vigliocco, G. 
(2012). Coming of age: A review of embodiment and the neuroscience of semantics. Cortex, 48(7), 788-804. doi: 10.1016/j.cortex.2010.11.002

Miller-Bottome, M., Talia, A., Eubanks, C. F., Safran, J. D., \& Muran, J. C. (2019). Secure in-session attachment predicts rupture resolution: Negotiating a secure base. Psychoanalytic Psychology, 36(2), 132. doi: 10.1037/pap0000232

Miller-Bottome, M., Talia, A., Safran, J. D., \& Muran, J. C. (2018). Resolving alliance ruptures from an attachment-informed perspective. Psychoanalytic Psychology, 35(2), 175. doi: $10.1037 /$ pap0000152

Nestel, D., Muir, E., Plant, M., Kidd, J., \& Thurlow, S. (2002). Modelling the lay expert for first-year medical students: the actor-patient as teacher. Medical Teacher, 24(5), 562-564. doi: 10.1080/0142159021000042649

Oberman, L. M., \& Ramachandran, V. S. (2008). How do shared circuits develop?. Behavioral and Brain Sciences, 31(1), 3435. doi: 10.1017/S0140525X07003263

Orlinsky, D. E., Ronnestad, M. H., \& Willutzki, U. (2004). Fifty years of psychotherapy process-outcome research: Continuity and change. In M. J. Lambert (Ed.), Bergin and Garfield's handbook of psychotherapy and behavior change (5th ed., pp. 307-389). New York, NY: Wiley.

Palmieri, A., Kleinbub, J. R., Calvo, V., Benelli, E., Messina, I., Sambin, M., \& Voci, A. (2018a). Attachment-security prime effect on skin-conductance synchronization in psychotherapists: An empirical study. Journal of Counseling Psychology, 65(4), 490-499. doi: 10.1037/cou0000273

Palmieri, A., Palvarini, V., Mangini, E., \& Schimmenti, A. (2018b). Transfert e controtransfert somatico: rassegna critica e integrazione con la prospettiva neuroscientifica. Rivista di Psichiatria, 53(6), 281-289. doi: 10.1708/3084.30761

Palumbo, R. V., Marraccini, M. E., Weyandt, L. L., WilderSmith, O., McGee, H. A., Liu, S., \& Goodwin, M. S. (2017). Interpersonal autonomic physiology: A systematic review of the literature. Personality and Social Psychology Review, 21(2), 99-141. doi: 10.1177/1088868316628405

Price, T. F., Peterson, C. K., \& Harmon-Jones, E. (2012). The emotive neuroscience of embodiment. Motivation and Emotion, 36(1), 27-37. doi: 10.1007/s11031-011-9258-1

Ramachandra, V., Depalma, N., \& Lisiewski, S. (2009). The role of mirror neurons in processing vocal emotions: evidence from psychophysiological data. International Journal of Neuroscience, 119(5), 681-691. doi: 10.1080/ 00207450802572188

Ramseyer, F., \& Tschacher, W. (2011). Nonverbal synchrony in psychotherapy: coordinated body movement reflects relationship quality and outcome. Journal of Consulting And Clinical Psychology, 79(3), 284. doi: 10.1037/a0023419

Ramseyer, F., \& Tschacher, W. (2014). Nonverbal synchrony of head-and body-movement in psychotherapy: different signals have different associations with outcome. Frontiers in Psychology, 5, 979. doi: 10.3389/fpsyg.2014.00979

Rocco, D., Gennaro, A., Salvatore, S., Stoycheva, V., \& Bucci, W. (2017). Clinical mutual attunement and the development of therapeutic process: a preliminary study. Journal of Constructivist Psychology, 30(4), 371-387. doi: 10.1080/10720537.2016.1227950

Salvatore, S. (2011). Psychotherapy research needs theory. Outline for an epistemology of the clinical exchange. Integrative Psychological and Behavioral Science, 45(3), 366. doi: 10.1007/s12124-011-9180-9

Salvatore, S., \& Gennaro, A. (2015). Outlines of a general theory of the psychotherapy process. The clinical exchange as communicational field: Theoretical considerations and methodological implications. In O. C. G. Gelo, A. Pritz, \& B. Rieken (Eds.), Psychotherapy research: Foundations, process, and outcome (pp. 195-212). New York, NY, US: Springer-Verlag Publishing.

Sampson, E. E. (1996). Establishing embodiment in psychology. Theory \& Psychology, 6(4), 601-624. doi: 10.1177/ 0959354396064004

Sander, L. W. (2002). Thinking differently principles of process in living systems and the specificity of being known. Psychoanalytic Dialogues, 12(1), 11-42. doi: 10.1080/ 10481881209348652

Shaw, R. (2004). The embodied psychotherapist: An exploration of the therapists' somatic phenomena within the therapeutic encounter. Psychotherapy Research, 14(3), 271-288. doi: $10.1093 / \mathrm{ptr} / \mathrm{kph} 025$

Skelton, J., Hammond, P., Fitzmaurice, D., \& Wiskin, C. (1997). The acceptability of whole-context role play. Education for General Practice, 8, 206-212.

Steinert, Y. (1993). Twelve tips for using role-plays in clinical teaching. Medical Teacher, 15(4), 283-291. doi: 10.3109/ 01421599309006651

Stiles, W. B., \& Shapiro, D. A. (1994). Disabuse of the drug metaphor: Psychotherapy process-outcome correlations. Journal of Consulting and Clinical Psychology, 62(5), 942948. doi: 10.1037/0022-006X.62.5.942

Stolorow, R. D. (2011). World, affectivity, trauma: Heidegger and post-Cartesian psychoanalysis. London, UK: Routledge/Taylor \& Francis Group.

Stolorow, R. D. (2013). Intersubjective-systems theory: A phenomenological-contextualist psychoanalytic perspective. Psychoanalytic Dialogues, 23(4), 383-389. doi: 10.1080/ 10481885.2013.810486

Stolorow, R. D., Atwood, G. E., \& Branchaft, B. (Eds.). (1994). The intersubjective perspective. Lanham, MD, US: Rowman \& Littlefield.

Talia, A., Muzi, L., Lingiardi, V., \& Taubner, S. (2018). How to be a secure base: therapists' attachment representations and their link to attunement in psychotherapy. Attachment \& Human Development, 1-18. doi: 10.1080/14616734. 2018.1534247

Tronick, E., Als, H., Adamson, L., Wise, S., \& Brazelton, T. B. (1978). The infant's response to entrapment between contradictory messages in face-to-face interaction. Journal of the American Academy of Child Psychiatry, 17(1), 1-13. doi: 10.1016/s0002-7138(09)62273-1

Tryon, W. W. (2016). Transtheoretic transdiagnostic psychotherapy. Journal of Psychotherapy Integration, 26(3), 273-287. doi: $10.1037 / \mathrm{a} 0040041$

Tschacher, W., \& Dauwalder, J. P. (2003). The dynamical systems approach to cognition: Concepts and empirical paradigms based on self-organization, embodiment, and coordination dynamics (Vol. 10). Singapore: World Scientific.

Tschacher, W., \& Pfammatter, M. (2016). Embodiment in psychotherapy - A necessary complement to the canon of common factors. European Psychotherapy, 13, 9-25. doi: 10.7892/boris. 93002

Tschacher, W., Munt, M., \& Storch, M. (2014). Die Integration von Tanz, Bewegung und Psychotherapie durch den Embodimentansatz. Körper-Tanz-Bewegung, 2, 54-63. doi: 10.2378/ktb2014.art10d

Tschacher, W., Storch, M., \& Munt, M. (2014). Tanz: eine psy- 
chotherapeutische Technik. Psychotherapie in Psychiatrie, Psychotherapeutischer Medizin und Klinischer Psychologie 19, 1-13.

Vacharkulksemsuk, T., \& Fredrickson, B. L. (2012). Strangers in sync: Achieving embodied rapport through shared movements. Journal of Experimental Social Psychology, 48(1), 399-402. doi: 10.1016/j.jesp.2011.07.015

Varela, F. J., Thompson, E., \& Rosch, E. (2017). The embodied mind: Cognitive science and human experience. Cambridge, MA: MIT Press.

Vermes, K. (2011). Intersensory and intersubjective attunement: Philosophical approach to a central element of dance movement psychotherapy. Body, Movement and Dance in Psychotherapy, 6(1), 31-42. doi: 10.1080/17432979.2010. 533823

Wallander, L. (2009). 25 years of factorial surveys in sociology: A review. Social Science Research, 38(3), 505-520. doi: 10.1016/j.ssresearch.2009.03.004
Wason, K. D., Polonsky, M. J., \& Hyman, M. R. (2002). Designing vignette studies in marketing. Australasian Marketing Journal, 10(3), 41-58. doi: 10.1016/S1441-3582(02) 70157-2

Waters, S. F., West, T. V., \& Mendes, W. B. (2014). Stress contagion: Physiological covariation between mothers and infants. Psychological Science, 25(4), 934-942. doi: 10.1177/0956797613518352

Winkielman, P., Niedenthal, P., Wielgosz, J., Eelen, J., Kavanagh, L. C. (2015). Embodiment of cognition and emotion. In M. Mikulincer, P. R. Shaver, E. Borgida, \& J. A. Bargh (Eds.), APA Handbook of Personality and Social Psychology, APA Handbooks in Psychology (pp. 151-175). Washington, WA, US: American Psychological Association. Winnicott, D. W. (1949/1992). Mind and its relation to psychesoma. In W. Winnicott (Ed.), Through paediatrics to psychoanalysis: Collected papers (pp. 243-254). London, UK: Karnac. 